Article

\title{
Dynamic Response of Satellite-Derived Vegetation Growth to Climate Change in the Three North Shelter Forest Region in China
}

\section{Bin He ${ }^{1,2, *}$, Aifang Chen ${ }^{1}$, Honglin Wang ${ }^{1}$ and Qianfeng Wang ${ }^{3}$}

1 Academy of College of Global Change and Earth System, Beijing Normal University, Beijing 100875, China; E-Mails: aifchen@126.com (A.C.); wanghonglin876@163.com (H.W.)

2 Joint Center for Global Change Studies, Beijing 100875, China

3 State Key Laboratory of Earth Surface Processes and Resource Ecology, Beijing Normal University, Beijing 100875, China; E-Mail: wangqianfeng23@163.com

* Author to whom correspondence should be addressed; E-Mail: hebin @bnu.edu.cn; Tel.: +86-10-5880-0059.

Academic Editors: Ioannis Gitas and Prasad S. Thenkabail

Received: 5 May 2015 / Accepted: 3 August 2015 / Published: 6 August 2015

\begin{abstract}
Since the late 1970s, the Chinese government has initiated ecological restoration programs in the Three North Shelter Forest System Project (TNSFSP) area. Whether accelerated climate change will help or hinder these efforts is still poorly understood. Using the updated and extended AVHRR NDVI3g dataset from 1982 to 2011 and corresponding climatic data, we investigated vegetation variations in response to climate change. The results showed that the overall state of vegetation in the study region has improved over the past three decades. Vegetation cover significantly decreased in $23.1 \%$ and significantly increased in $21.8 \%$ of the study area. An increase in all three main vegetation types (forest, grassland, and cropland) was observed, but the trend was only statistically significant in cropland. In addition, bare and sparsely vegetated areas, mainly located in the western part of the study area, have significantly expanded since the early 2000s. A moisture condition analysis indicated that the study area experienced significant climate variations, with warm-wet conditions in the western region and warm-dry conditions in the eastern region. Correlation analysis showed that variations in the Normalized Difference Vegetation Index (NDVI) were positively correlated with precipitation and negatively correlated with temperature. Ultimately, climate change influenced vegetation growth by controlling the availability of soil moisture. Further investigation suggested that the positive impacts of
\end{abstract}


precipitation on NDVI have weakened in the study region, whereas the negative impacts from temperature have been enhanced in the eastern study area. However, over recent years, the negative temperature impacts have been converted to positive impacts in the western region. Considering the variations in the relationship between NDVI and climatic variables, the warm-dry climate in the eastern region is likely harmful to vegetation growth, whereas the warm-wet conditions in the western region may promote vegetation growth.

Keywords: climate change; vegetation growth; NDVI; ecological restoration programs; China

\section{Introduction}

Beginning in 1978, the Chinese government launched ambitious afforestation programs such as the Three North Shelter Forest System Project (TNSFSP) to cope with environmental degradation and desertification [1]. Two other major ecological restoration programs, the Beijing-Tianjin Sand Source Control Program [2] and the Grain for Green Project [3], were also implemented in this region. The rationale and effectiveness of these ecological restoration projects in arid and semiarid areas with fragile environments have been continuously debated [4-6]. Some studies have claimed that desertification has significantly declined and vegetation growth has increased in this region over the past few decades $[7,8]$. However, other authors have suggested that the importance of these projects has been overstated $[1,9,10]$, noting that deserts have continued to expand and sandstorms have increased over recent years in the TNSFSP area [1]. Cao [1] warned that afforestation in arid and semiarid regions is likely to increase environmental degradation. With the acceleration of climate change, these restoration projects have become even more controversial.

In recent years, tree mortality in the Three North Shelter Forest has been frequently reported by the media and studies [11]. Frequent droughts and decreased precipitation related to climate change have been suspected as the reasons for the tree deaths. This raises the following questions: (1) To what extent has vegetation declined? (2) Will climate change support or damage the efforts of ecological projects in this region? To answer these questions, an in-depth understanding of vegetation changes and their responses to climate change is needed.

The Normalized Difference Vegetation Index (NDVI) is a good indicator of various vegetative biophysical parameters, such as biomass, green leaf area index, and percent green cover [12], which can be used to measure vegetation change. The NDVI demonstrates strong linear relationships with environmental variables such as temperature and precipitation under various environmental circumstances [13]. The NDVI is one of the most important indicators of the effectiveness of ecological restoration projects [8]. It has also been widely used to monitor climate change effects [14], the terrestrial carbon cycle [15], and land cover change [16]. Several studies have focused on variations in vegetation in northern China. The national average NDVI has markedly increased over the past few decades [17]. The increase was also confirmed to be significant over a large area of the Three North Shelter Forest from 1982 to 2006 [18]. However, a recent study pointed out that little change occurred in northern China from 1982 to 2010 and vegetation growth has been suppressed by enhanced warming and reduced precipitation since the 1990s [19]. In addition, some researchers have investigated changes in the NDVI 
in some sub-regions of the TNSFSP area such as the Beijing-Tianjin Sand Source Region [2], Horqin Sandy Land [8], and Inner Mongolia [20,21]. These studies indicated changes in vegetation and demonstrated the close link between plant growth and climate change in this region. However, certain issues still require clarification. First, the changes within various vegetation types are still poorly understood. Second, the characterization of variations in bare and sparsely vegetated areas requires improvement. Third, moisture variations due to climate change and their potential impacts on vegetation growth are unclear.

In 2010, the fourth phase of the TNSFSP (with a total of seven phases) and the first construction phase of the Beijing-Tianjin Sand Source Control Program were completed (2001-2010). In addition, the Grain for Green Project was finished in 2010 (1999-2010). At this time, there is an urgent need to assess the effects of these programs. Therefore, the goal of this study was to monitor and assess the vegetation conditions in the TNSFSP area based on the updated and extended AVHRR NDVI3g dataset from 1982 to 2011 . We also investigated the dynamics of the response of vegetation growth to climate change. The results are critical for guiding local environmental protection policies.

\section{Data and Methods}

\subsection{Study Area}

The TNSFSP area is located in Northern China $\left(73^{\circ} 26^{\prime} \mathrm{E}-127^{\circ} 50^{\prime} \mathrm{E}\right.$ and $\left.33^{\circ} 30^{\prime} \mathrm{N}-50^{\circ} 12^{\prime} \mathrm{N}\right)$ and includes 13 provinces and autonomous regions (Figure 1). The entire region accounts for $42.4 \%$ of China's total area, two-thirds of which is characterized by arid and semi-arid regions with an annual average precipitation of less than $200 \mathrm{~mm}$. The arid climate and intensive anthropogenic interferences make it one of the most environmentally vulnerable regions of China, and it is often the origin of sandstorms. A detailed description of the regional climate and geographical characteristics is available in Duan et al. [18].

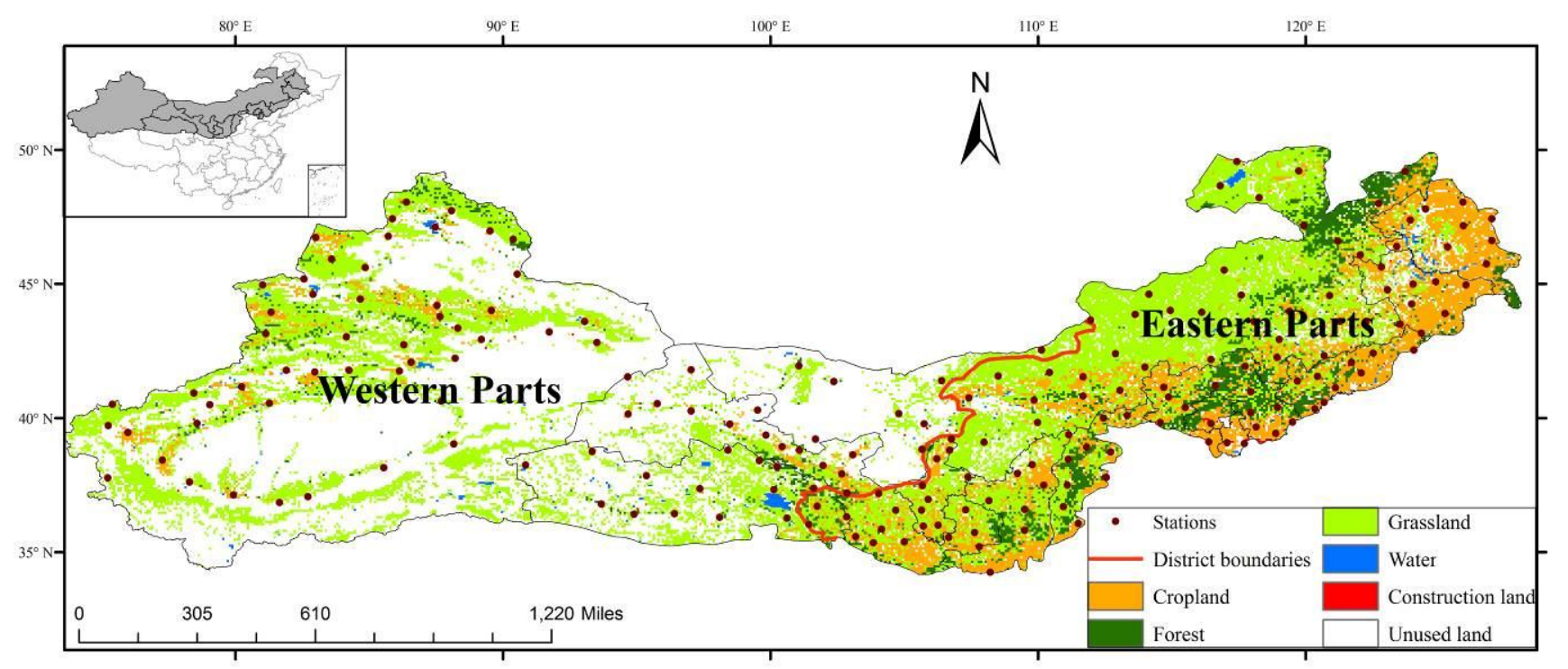

Figure 1. Map of the research area showing the distribution of land-use types and climate stations. A land-use map from the late 1980s was used. 


\subsection{Datasets}

The NDVI data (from 1982 to 2011) used in this study were derived from an updated version of the AVHRR NDVI3g dataset, which has a spatial resolution of $8 \times 8 \mathrm{~km}^{2}$ and a temporal resolution of 15 days. This dataset is an upgraded version of the AVHRR NDVIg dataset. The two versions (old and upgraded) of the NDVI dataset were both developed by the Global Inventory Modeling and Mapping Studies (GIMMS) project [22]. Compared to the old version, the AVHRR NDVI3g dataset has a finer spatial resolution, longer time interval, and higher vegetation activity detection accuracy [23]. The reliability of this dataset has been assessed in many studies [23,24], and it has been widely used in research on vegetation in China [19,25]. The maximum value composite (MVC) method was used to reduce noise in the data and generate the monthly NDVI series [26]. A threshold of 0.1 [17] was used to classify "vegetated areas" (NDVI $\geq 0.1$ ) and "bare and sparsely vegetated areas" (NDVI < 0.1 ). The average annual NDVI value was determined to explore the yearly variations in the bare and sparsely vegetated areas. To ensure that the vegetation change analysis was carried out over the same areas, the vegetated areas were determined as those areas with an average NDVI $\geq 0.1$ from 1982 to 1991. In addition, this study was confined to the growing season (April-October) [19].

The monthly mean temperature and precipitation as well as other climatic data from 204 stations throughout the study area from 1982 to 2011 were obtained from the Chinese Meteorological Administration. Quality control for all station data was performed station by station by manually checking observations for outliers. To match the spatial resolution with that of the NDVI dataset, all climatic variables were interpolated to grid cells with a resolution of $8 \times 8 \mathrm{~km}^{2}$ using the Kriging interpolation algorithm [27,28].

A 1:1,000,000 vegetation map of China [29] was used to explore the vegetation changes in different biome types. Following the criteria for biome type classification, vegetation in the study area was categorized into three main types: forest, grassland, and cropland. In addition, for convenience of description, we divided the whole region into two sub-regions (western and eastern regions) according to climatic divergences (Figure 1).

\subsection{Methods}

Trends in the NDVI and climatic factors were determined for each pixel using Sen's slope estimator [30]. Generally, parametric (distribution-dependent) or non-parametric (distribution-free) statistical tests can be used to detect whether a statistically significant trend exists. With parametric tests, it is necessary to assume an underlying distribution of the data (often a normal distribution) and that observations are independent of one another [31]. In non-parametric and distribution-free methods, fewer assumptions about the data need to be made [32]. With such methods, it is not necessary to assume a distribution. Sen's slope estimator is a non-parametric (distribution-free) statistical test; therefore, the data do not need to be normally distributed. Calculating the Sen's slope estimator requires a time series of equally spaced data, and the data in our study meet this requirement. Sen's method proceeds by calculating the slope as a change in measurement per change in time. This robust non-parametric method has been used in hydro-meteorological and vegetation time series [33,34]. For each variable, positive 
slopes indicate an increasing trend, whereas negative slopes indicate a decreasing trend. Significant slopes were assumed for $p<0.05$.

Temperature and precipitation are the two most important climatic parameters affecting vegetation change. To explore the sensitivity of vegetation change to climatic variables, the correlations between NDVI and two common climate variables (temperature and precipitation) were determined for each pixel during the study period. Furthermore, to explore how the above correlations changed over the time, the correlations in each sub-region were calculated over different time intervals (using a 15-year moving window). The correlation coefficient for each 15-year window was assigned to the central year; for example, 1989 represents the moving window from 1982 to 1996.

Penman's moisture index [35] was used to explore variations in the boundaries of different climatic regions. This index serves to describe the atmospheric water conditions of a region and has been widely used in studies of climate change, acidification, and desertification [36]. Penman's moisture index was computed as follows:

$$
I_{m}=\frac{P E}{P}
$$

where $I_{m}$ is the moisture index, $P E$ is Penman's potential evapotranspiration, and $P$ is precipitation. The value of $P E$ was computed using the standard Penman-Monteith method recommended by the Food and Agricultural Organization (FAO), as follows:

$$
P E=\frac{0.408 \Delta\left(R_{n}-G\right)+\gamma \frac{900}{T+273} U_{2}\left(e_{s}-e_{a}\right)}{\Delta+\gamma\left(1+0.34 U_{2}\right)}
$$

where $\Delta$ represents the slope of the saturation vapor pressure-temperature relationship $\left(\mathrm{kPa} /{ }^{\circ} \mathrm{C}^{-1}\right), R n$ is the net solar radiation $\left(\mathrm{MJm}^{-1} \cdot \mathrm{d}^{-1}\right), G$ is the soil heat flux $\left(\mathrm{MJm}^{-1} \cdot \mathrm{d}^{-1}\right), \gamma$ is the psychrometric constant $\left(\mathrm{kPa} /{ }^{\circ} \mathrm{C}^{-1}\right), T$ is mean daily air temperature at $2-\mathrm{m}$ height $\left({ }^{\circ} \mathrm{C}\right), U_{2}$ is the wind speed at $2-\mathrm{m}$ height $\left(\mathrm{m} \cdot \mathrm{s}^{-1}\right), e_{s}$ is the saturation vapor pressure $(\mathrm{kPa})$, and $e_{a}$ is the actual vapor pressure deficit $(\mathrm{kPa})$.

$R n$ was calculated with following formula:

$$
R_{n}=0.77 \times\left(a+b \frac{n}{N}\right) R_{s o}-\sigma\left(\frac{T_{\max , K^{4}}+T_{\min , K^{4}}}{2}\right)\left(c-d \sqrt{e_{a}}\right)(e+f n / N)
$$

where $\sigma$ is Stefan-Boltzmann constant $\left(4.903 \times 10^{-9} \mathrm{MJ} \cdot \mathrm{K}^{-4} \cdot \mathrm{m}^{-2} \cdot\right.$ day $\left.^{-1}\right), N$ is the maximum possible duration of sunshine, $n$ is the actual sunshine duration, $R_{s o}$ is the clear-sky solar radiation, and $T_{\max , k}$ and $T_{\min , k}$ are the maximum and minimum temperature $(\mathrm{K})$, respectively. The empirical parameters $a=0.248, b=0.752, c=0.56, d=0.08, e=0.1$, and $f=0.9$ were recommended by Wu et al. [37].

Penman's moisture index has been shown to perform well in both arid and humid climates throughout the world [37]. Detailed information on the Penman-Monteith method and the climatic categories based on $I_{m}$ is available in $\mathrm{Wu}$ et al. [37]. 


\section{Results}

\subsection{Vegetation Change from 1982 to 2011}

\subsubsection{Spatial Patterns of Growing-Season NDVI}

The spatial distribution of linear trends in growing-season NDVI from 1982-2011 are shown in Figure 2. Green areas indicate increasing vegetation cover, and red areas represent a decreasing trend. Overall, vegetation in the study region increased over the study period. Vegetation cover significantly decreased in $23.1 \%$ and significantly increased in $21.8 \%$ of the study area (Figure S1). Significant increases occurred in the southeastern, southern, and western parts of the study region. Areas showing significant decreases in NDVI were distributed mainly in the eastern part of Inner Mongolia and scattered along edges of deserts in the western study region. A decline in vegetation in this area was also reported by Duan et al. [18], but the extent was less than that observed in this study from 1982 to 2006.

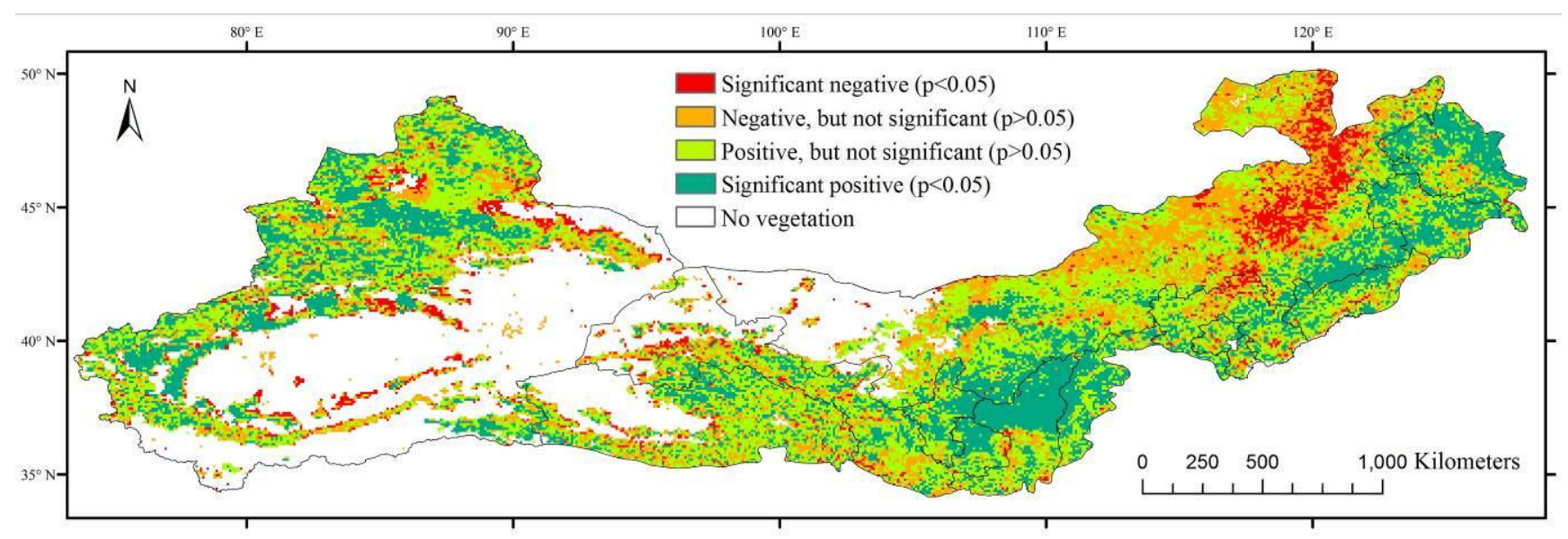

Figure 2. Spatial distribution of changes in growing-season NDVI (Normalized Difference Vegetation Index) from 1982 to 2011. Red areas represent decreasing trends, and green areas represent increasing trends.

Vegetation variations over different time intervals were investigated by dividing the entire study period into six intervals (1982-1986, 1987-1991, 1992-1996, 1997-2001, 2002-2006, 2007-2011) and calculating the difference in the mean NDVI value of each period relative to the first stage (1982-1986) (Figure S2). Compared with the first stage, extensive NDVI increases occurred during the third (2002-2006) and sixth (2007-2011) stages, whereas extensive NDVI decreases occurred in the fourth (1997-2001) and fifth (2002-2006) stages.

\subsubsection{Vegetation Change by Land-Cover Type}

Using a vegetation type map, we explored the NDVI variations of different vegetation types, including forests, grassland, and cropland. As shown in Figure S3, the average growing-season NDVI over the whole region significantly increased at a rate of $0.00052 \mathrm{yr}^{-1}$, reflecting improved vegetation conditions. The largest significant increase $\left(0.0017 \mathrm{yr}^{-1}\right)$ in growing-season NDVI occurred in cropland. The spatially averaged NDVI for grassland and forest combined exhibited an upward trend but no 
significant change. The variations in NDVI for these three land types showed a similar trend that could be divided into three periods. From 1982 to 1999, the NDVI values continually increased. Then, the NDVI values sharply decreased and stabilized at a low level. After 2007, there was no obvious increasing trend for any vegetation type.

Table S1 summarizes the percentage of NDVI variations for the three main vegetation types. For each type, areas with increasing NDVI were all greater than those with decreasing NDVI, providing further evidence of increasing vegetation cover in the TNSFSP area. Grassland was the most widely distributed vegetation type. The NDVI in $22.7 \%$ of grassland areas significantly increased, whereas only $10.6 \%$ of these areas showed a significant decrease. The most notable increase in NDVI occurred in croplands, which have been seriously affected by human activities such as irrigation, fertilization, and crop modifications: the NDVI values significantly increased in $48.9 \%$ of cropland areas and significantly decreased in only $2.1 \%$ of these areas. Compared to the above two land types, forests had the largest area of significantly decreasing NDVI (14.0\%), which supports media reports about forest mortality. Although forests account for only a small proportion of total vegetated areas, they play an important role in withstanding sandstorms, and this decline cannot be ignored.

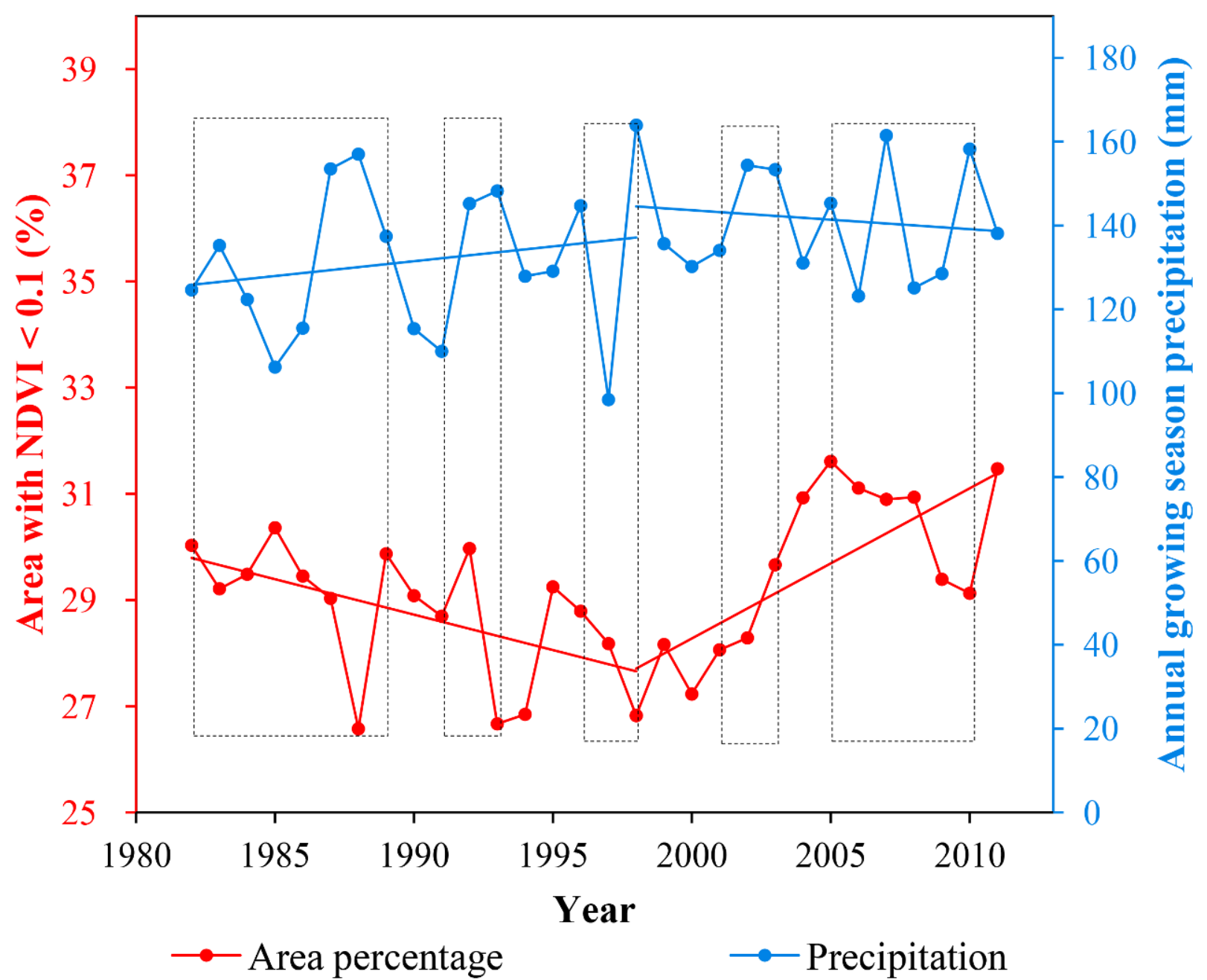

Figure 3. Annual variations in bare and sparsely vegetated areas (red line) and annual precipitation in the western study region (blue line) from 1982 to 2011 . Boxes indicate reverse trends of precipitation and area percentage. 


\subsubsection{Variations in Bare and Sparsely Vegetated Areas}

As shown in Figure 3, bare and sparsely vegetated areas (NDVI $<0.1$ ) have increased over the past three decades. In 1982, bare and sparsely vegetated areas accounted for about $30 \%$ of the total study area. In 2011, they amounted to 31.5\%. Two phases could be identified: before 1998, bare and sparsely vegetated areas continually decreased; however, after 1998, they rapidly increased. Figure 3 also demonstrates the annual precipitation variations in the western region, where bare and sparsely vegetated areas were mainly distributed (Figure S4). Before 1998, inverse relationships could be identified between the annual precipitation and area ratio of bare and sparsely vegetated areas (Figure 3), suggesting that precipitation was the dominant driving force of the variations in bare and sparsely vegetated areas over this period. However, the sharp increase in bare and sparsely vegetated areas after 1998 appeared to be caused by rapid warming in the western region (see Section 3.2.2).

Figure S4 illustrates the spatial variability of bare and sparsely vegetated areas over the past three decades. In the $1990 \mathrm{~s}$, about $22,000 \mathrm{~km}^{2}$ of vegetated areas became bare and sparsely vegetated areas and $62,000 \mathrm{~km}^{2}$ experienced the reverse process compared to the $1980 \mathrm{~s}$. During the $2000 \mathrm{~s}$, the increase in bare and sparsely vegetated areas $\left(79,000 \mathrm{~km}^{2}\right)$ was significantly greater than the increase in vegetated areas $\left(29,000 \mathrm{~km}^{2}\right)$. Bare and sparsely vegetated areas mainly increased in the western region. From the 1990s to the 2000s, bare and sparsely vegetated areas increased dramatically. The new bare and sparsely vegetated areas mainly originated from grassland and forests.

\subsection{Climate Change and its Relationship with Vegetation Growth}

\subsubsection{Climate Change}

From 1982 to 2011, significant climate change was observed in the study area (Figure S5). Throughout the study area, the mean surface temperature increased by $1.4{ }^{\circ} \mathrm{C}$ and rainfall decreased by $7.6 \mathrm{~mm}$. Figure S5a,b show spatial variations in the linear trends of precipitation and temperature, respectively. Rainfall decreased in the eastern region but increased in the western region. Most of the study area experienced strong warming associated with global and national warming. Due to changes in temperature and precipitation, the western region shifted towards a warm-wet climate, whereas the eastern region shifted towards a warm-dry climate. Previous studies have also noted a climate transition to warm-wet conditions in northwest China [38] and warm-dry conditions in northeast China [39].

Moisture indices have been previously used to determine the moisture conditions and water balance of a given area [40]. Based on Penman's moisture index, moisture conditions in the study area were classified into four climate types: humid, sub-humid, semiarid, and arid. The spatio-temporal changes in different climate regions are shown in Figure 4. Most parts of the study area were classified as having arid and semiarid climates, in which the water demand exceeded the supply. From the 1980s to the 2000s, the boundary of the semiarid region in the eastern region shifted eastward with some sub-humid areas becoming semiarid, indicating a drying trend in these areas. Semiarid areas also expanded in the northwestern study area; this change from an arid to semiarid climate implied a wetting trend in these areas. The area percentage of different climate divisions for the 1980s, 1990s, and 2000s is shown in Table S2. Areas of humid, sub-humid, and arid climate regions all diminished, whereas semiarid regions significantly expanded. The above analysis suggests that climate differentiations are occurring 
throughout the study area. The western region is becoming warmer and wetter, whereas the eastern region is becoming warmer and drier.

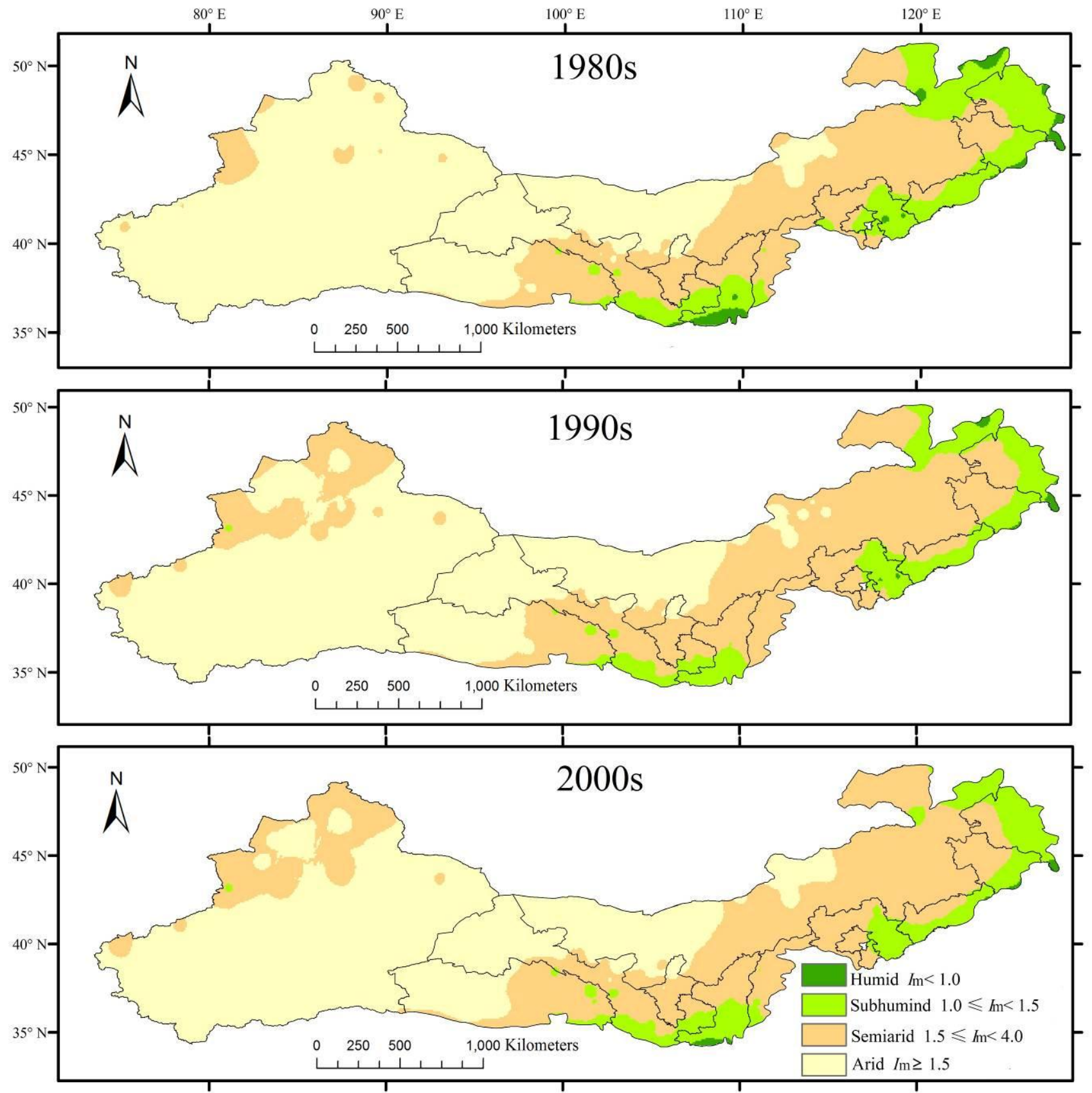

Figure 4. Spatio-temporal changes in different climate regions (1982-2011). Climate regions were defined and classified by Penman's moisture index (Equation (1)).

\subsubsection{Influence of Climate Change on Vegetation}

Climate change is one of the most important factors driving vegetation growth. The close relationship between climate change and vegetation growth has been demonstrated in many previous studies [19,41].

The spatial patterns of the correlation coefficients for the relationships between growing-season NDVI and corresponding precipitation and temperature are shown in Figure 5a,b, respectively. Except for a few areas in the eastern study area, most areas displayed significant positive correlations between 
NDVI and rainfall. This finding is consistent with previous studies [18,20] that have reported the decisive role of precipitation in vegetation growth in areas with arid or semi-arid climates.
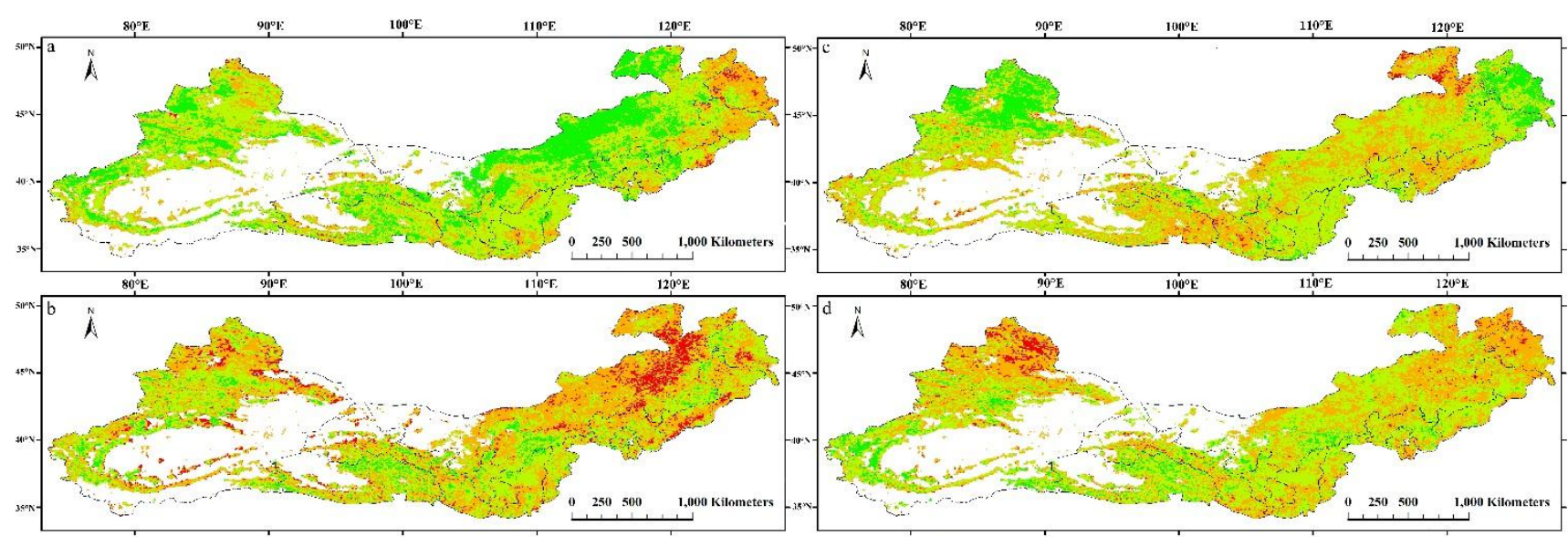

Significant negative $(\mathbf{p}<0.05)$

Negative, but not significant $(p>0.05)$

Positive, but not significant $(\mathrm{p}>0.05)$

Significant positive $(\mathbf{p}<\mathbf{0 . 0 5})$

$\square$ No vegetation

Figure 5. Correlations between growing-season NDVI and (a) corresponding precipitation, (b) corresponding temperature, (c) pre-growing season precipitation, and (d) temperature from 1982 to 2011. Correlations were considered significant for $p<0.05$. Red areas represent negative relationships, and green areas represent positive relationships.

In contrast to the positive relationship between NDVI and precipitation, an inverse NDVI-temperature relationship was observed over most of the study area. As discussed above, most of the study area experienced significant warming. Although the warming trend should extend the growing season and potentially enhance vegetation growth $[17,42,43]$, extension of the growing season may lead to increased water scarcity caused by accelerated evaporation [20].

The climatic conditions during the pre-growing season also impacted the growing-season NDVI. The correlations between pre-growing season precipitation and temperature and growing-season NDVI are shown in Figure 5c,d. Similar to the relationship between growing-season NDVI and corresponding precipitation, pre-growing season precipitation generally had a positive impact on NDVI in both the eastern and western regions. The impacts of pre-growing season temperature on NDVI were very complex, with positive and negative correlations throughout the study region. Significant positive correlations occurred near the edges of deserts, indicating that pre-growing season warming was beneficial to vegetation growth. However, negative correlations were measured in the eastern and northwestern regions.

To further explore the response of vegetative biomes to climatic factors, the correlations between growing-season NDVI for each vegetation type and corresponding precipitation and temperature were extracted from Figure 4. In forests, the negative effect of temperature was more apparent than the positive impact of precipitation, indicating that the marked warming in this area harmed the forest vegetation (Figure S6). High spatial consistency of the positive impact of precipitation was observed in grasslands. Temperature and NDVI were negatively correlated except for in small areas of the central and western regions. Human activities strongly affected the NDVI in croplands. For this reason, the relationships between NDVI and climatic factors were relatively complex. Although both negative and 
positive effects of precipitation and temperature were observed, the area experiencing positive precipitation effects $(11.07 \%)$ was larger than that experiencing negative effect $(2.25 \%)$. Conversely, the area undergoing negative temperature effects was larger than that with positive effects.

In arid and semi-arid ecosystems, water availability is the dominant factor for vegetation growth. Soil moisture availability depends on the balance between precipitation and evapotranspiration. In this analysis, the response of vegetation growth to soil moisture was investigated based on Penman's moisture index, as shown in Figure 6. With the exception of small areas in the eastern study region, a negative relationship between growing-season NDVI and corresponding $I_{m}$ was found throughout the study area from 1982 to 2011. Significant relationships were concentrated in the eastern study region. This close relationship suggests that climate change influences vegetation growth by controlling the availability of soil moisture.

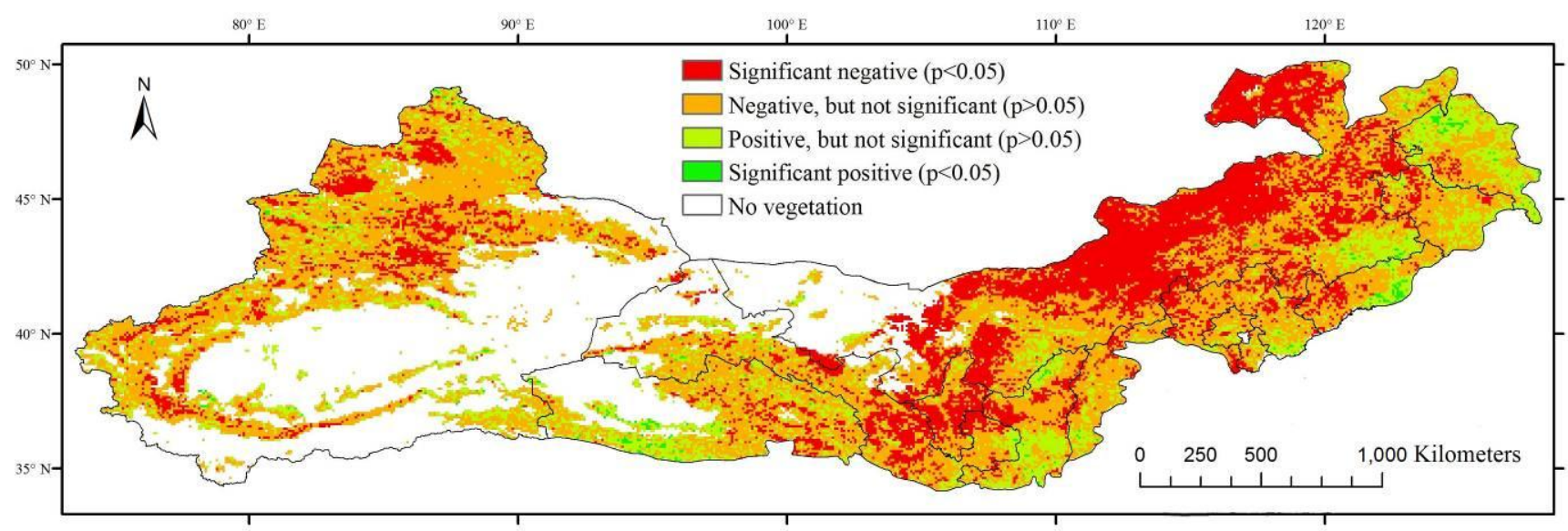

Figure 6. Correlations between growing-season NDVI and corresponding soil moisture $\left(I_{m}\right)$ from 1982 to 2011. Correlations were considered significant for $p<0.05$. Red areas represent negative relationships, and green areas represent positive relationships.

\subsubsection{Vegetation Growth and Its Relationship with Climate Change in Sub-Regions}

The above analysis suggests that dramatic differences exist between the climate conditions in the western and the eastern study regions (Figures 4 and S5). Thus, to further analyze the relationships between climate change and vegetation growth, we divided the whole region into two sub-regions (western and eastern) and analyzed the trends of growing-season NDVI, precipitation, and temperature in each region (Figure 7). The NDVI in both regions showed an increasing trend, but significant increases were only observed in the western region. In general, the growing-season precipitation was weakly increased in the western region and decreased in the eastern region. The growing-season temperature mainly increased in both regions.

The NDVI variation in the western region appeared to be related to precipitation during the beginning of the study period (Figure 7a1-a3). Increasing temperature likely caused the increased vegetation growth during the later part of the study period. This is not difficult to understand, as warming-related snowmelt may play an important role in boosting vegetation growth in this area [44]. In the eastern region, although precipitation was the main driving force of NDVI during the early years, the sharp increase in NDVI over more recent years did not appear to be related to decreasing precipitation 
(Figure 7b1-b3). The apparent inverse relationship between NDVI and temperature during recent years indicated that the sharp increase in NDVI was not caused by temperature. Therefore, we speculate that human activities may be the main reason for this observed increase. First, the majority of TNSFSP cropland is located in this region, and as noted above, the NDVI in cropland is sensitive to human activities. Second, the Beijing-Tianjin Sand Source Control Program, was implemented in this region in 2000, and this large restoration project has promoted vegetation growth [2]. It is worthwhile to note that the NDVI in both regions apparently decreased in $~ 2000$, likely as a result of low precipitation and high temperature.
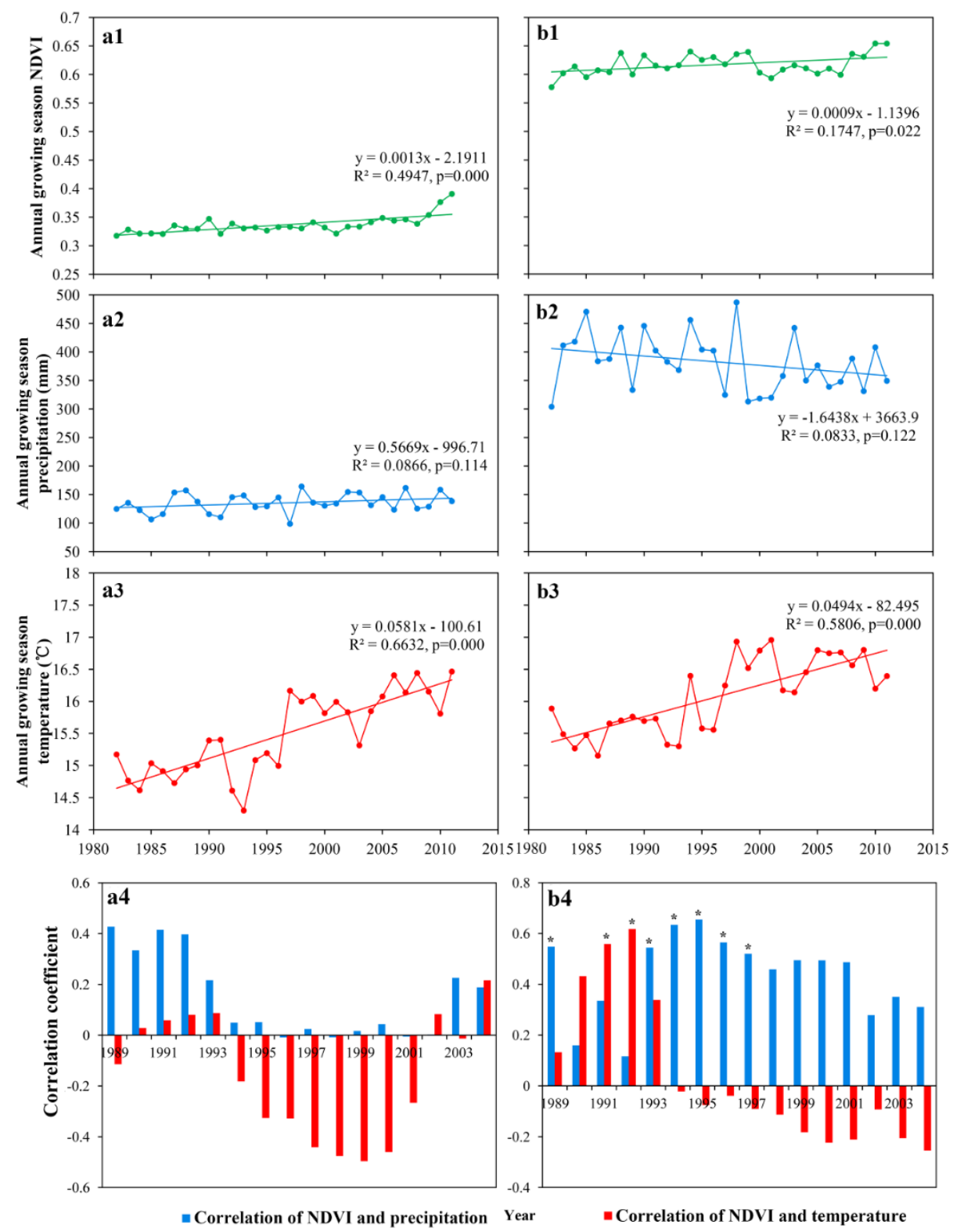

Figure 7. Interannual variations in (a1, b1) growing-season NDVI, (a2, b2) growing-season precipitation, and $(\mathbf{a 3}, \mathbf{b 3})$ growing-season temperature and the correlation coefficients between NDVI and (a4) precipitation and (b4) temperature based on 15-year moving windows in the two sub-regions. The letter "a" represents the western region, and "b" represents the eastern region. * Significant correlation at $p<0.05$. 
In the western region, a persistent positive relationship between NDVI and precipitation was observed over 15-yr moving windows (Figure 7a4,b4). The decreased magnitude of the correlation coefficients in the more recent 15-yr intervals suggests weakened impacts of precipitation on vegetation growth. The value of the NDVI-temperature correlation coefficient was negative during the first 15-yr interval (1982-1996) but positive during the last 15-yr interval (1997-2011), indicating a conversion from negative to positive impacts of temperature on vegetation. The higher value of the NDVI-temperature correlation coefficient compared to the NDVI-precipitation correlation coefficient indicates that temperature had a stronger effect on vegetation growth than precipitation during the more recent 15 -yr intervals.

We also observed a reduced positive relationship between precipitation and NDVI in the eastern region. In contrast to the western region, a positive relationship existed between temperature and NDVI during the first 15-yr interval and a negative relationship existed during the last, suggesting that increased warming was harmful to vegetation growth. In addition, precipitation had a stronger impact on vegetation growth than temperature, as indicated by the higher magnitude of the NDVI-precipitation correlation coefficient compared with the NDVI-temperature correlation coefficient.

Furthermore, the effects of $\mathrm{CO}_{2}$ concentration on vegetation growth were examined (Figure S7). There was no significant relationship between $\mathrm{CO}_{2}$ concentration and NDVI in both sub-regions, and thus no effect of $\mathrm{CO}_{2}$ on vegetation growth in the study area.

Considering the variations in the relationships between NDVI and climatic variables, the warm-dry climate in the eastern region was likely harmful to vegetation growth, whereas the warm-wet conditions in the western region promoted vegetation growth.

\section{Discussion}

Over the past several decades, the Chinese government has made efforts to save the fragile environment in the TNSFSP area. These efforts have included afforestation, grassland fencing, grazing prohibition, and other practices. Table S3 lists the main ecological projects in the TNSFSP area. The vegetation growth throughout the area as a whole improved from 1982 to 2011 , and this should be partly attributed to ecological restoration programs, especially in the eastern study region. From 2001 to 2010, afforested areas in the TNSFSP and Beijing-Tianjin Sand Source Control Program regions reached $275,000 \mathrm{~km}^{2}$ and $55,000 \mathrm{~km}^{2}$, respectively [45]. Vegetation cover in this region has improved to various degrees. From 2001 to 2007, the mean vegetation cover increased by $2.07 \%$ following the implementation of restoration projects [46]. A longer time series analysis (1982-2006) supported this finding [10].

However, the close relationship between vegetation change and climatic factors suggests that climate change may play an increasingly important role in vegetation dynamics in the future, although it is difficult to quantify its exact contribution. A large proportion of the TNSFSP area consists of arid and semi-arid ecosystems. In this study, soil moisture was found to have the closest relationship with vegetation activity, and this finding is consistent with previous investigations in semi-arid ecosystems [47,48]. A previous study also suggested that climate change has a stronger effect on environmental change in North China than human activities [49]. Another main finding of the current study was that the positive impacts of precipitation on NDVI have weakened. Moreover, the negative 
impacts of temperature have been enhanced in the eastern study region, but these negative effects have become positive in the western region over recent years. The reduced positive effects of precipitation and enhanced negative effects of temperature on vegetation growth in the eastern region were attributed to decreasing precipitation and warming-related soil drying. The change in the influence of temperature on vegetation growth from negative to positive may be explained by warming-related snowmelt. The variations in the relationship between climatic variables and NDVI imply potential adverse effects of climate change on vegetation growth, especially in the eastern region. In addition, Wang et al. reported that rising aerosol concentrations caused by increasing air pollution and atmospheric deposition also threaten vegetation growth in this region [50]. Rising aerosols constrain vegetation growth by decreasing radiation, and thereby increasing cloud coverage.

The warm-wet climate observed in the western study region is presumed to be beneficial to vegetation growth in the short term, and the recent increase in NDVI supports this viewpoint. However, the observed large increase in temperature but small increase in precipitation during the growing season should cause drying due to elevated evapotranspiration, especially in arid climates. This may explain why the areas experiencing significant decreases in NDVI have expanded over recent years compared to the results from a previous study in this area from 1982 to 2003 [44]. The expansion of areas with decreased vegetation cover occurred mainly near the edges of deserts, as did the expansion of bare and sparsely vegetated areas. Given the inverse relationship between temperature and vegetation growth, continued warming is likely the main reason for the rapid expansion of bare and sparsely vegetated areas over recent years. However, the influence of human activity should be considered as well.

The increasingly warm and dry conditions in the eastern study region may cause vegetation cover to decline, as observed in eastern Mongolia. Although vegetation in some areas increased, further investigation revealed that these increases were mainly in croplands, which have been significantly influenced by irrigation. Another reason for the NDVI increase in recent years is the implementation of the Beijing-Tianjin Sand Source Control Program in 2000. However, strong evapotranspiration due to promoted vegetation activity and extensive irrigation may deplete groundwater and accelerate environmental degradation in this region [9].

Another feature of climate change is the increase in extreme climatic events such as droughts, heat waves, and rainstorms. Adverse effects of drought on vegetation growth have been frequently reported in China [19,51]. Xu et al. [52] suggested that the increase in extreme drought events was responsible for the decrease in vegetation in North China during the 2000s. Several modeling studies have projected that drought events in North China will increase in the future. For example, using a regional climate model (RegCM3), Liu et al. [53] predicted an increase in drought events in Northeast China over the 21 st century. However, a recent projection by Wang and Chen [54] was somewhat different. Based on their results, the projected drought risk for North China is relatively low during the early to middle 21st century under two emission scenarios (RCP 4.5 and RCP 8.5). However, towards the end of the 21 st century, the frequency and severity of droughts will increase dramatically based on RCP 8.5. In spite of the uncertainty in drought projections, the potential impacts of drought on vegetation growth cannot be ignored.

In addition, variations in NDVI also affect regional climate by altering surface albedo and evapotranspiration, and thereby impacting the regional energy budget [52]. Peng et al. [55] demonstrated that afforestation in dry regions causes increased warming and suggested that the potential climatic 
effects of afforestation projects should be assessed. Feedback mechanisms between precipitation and vegetation can affect arid and semiarid areas. It is possible that vegetation reductions due to precipitation deficits cause an increase in surface albedo, thereby cooling the air, which in turn causes a decrease in precipitation [56]. This positive feedback loop may accelerate the decline of vegetation. In the TNSFSP area, the interaction between the climate system and vegetation variation is still poorly understood and further investigation is needed in the form of combined field experiments and process-based modeling.

Uncertainties still remain in the understanding of the response of vegetation growth to climate change in the TNSFSP area. First, only the AVHRR NDVI3g dataset was used to detect vegetation activity in this study. Despite the fact that the dataset's accuracy has been greatly improved compared to the older version (AVHRR NDVIg), satellite-based data always involves uncertainty due to sun-sensor-surface viewing geometries, atmospheric conditions (e.g., vapor, cloud, and aerosols), and sensor performance [23]. Future studies are needed to assess its reliability by comparing results to those based on other datasets such as ecological data from field observations and other higher-quality satellite-derived NDVI datasets (e.g., MODIS NDVI). Second, uncertainties were also produced by the data processing methods. For example, the accuracy of the interpolated climatic data may be greatly impacted by the interpolation method used, topographic conditions, the number of stations, and so on [57]. Third, the results from this study were based on linear regression analyses, and thus the basic presumption that a linear relationship exists between vegetation growth and climatic variables. However, some recent studies have suggested that these relationships are not linear in all regions and biomes. For example, a study on the response of grassland to climate change in northern Arizona [58] indicated a nonlinear response of vegetation growth to warming during the initial stages of the study period. However, after a certain time interval, the positive effects of warming on vegetation growth progressively declined owing to warming-related plant community alteration, soil nitrogen turnover, etc. All the above-mentioned issues should be included in future investigations.

\section{Conclusions}

Vegetation growth is an important indicator of the effectiveness of ecological restoration projects in the TNSFSP area. This study comprehensively assessed the dynamics of vegetation activity from 1982 to 2011. Furthermore, the relationships between vegetation growth and climatic variables were examined over different time intervals. The main conclusions of this study are as follows.

1. From 1982 to $2011,23.1 \%$ of the vegetated area in the study region had a significant decrease in vegetation cover, which was higher than that having a significant increase $(21.8 \%)$.

2. The bare and sparsely vegetated areas increased from $30 \%$ of the total study area in 1982 to $31.5 \%$ in 2011.

3. Generally, growing-season NDVI responded positively to precipitation but negatively to temperature. Climate change ultimately influences vegetation growth by controlling the availability of soil moisture.

4. The arid region reduced from $57.4 \%$ of the total study area in 1980 s to $51.82 \%$ in the 2000 s, mainly caused by a warm-wet climate trend in the western study region; and the humid region shrunk from $1.2 \%$ in 1980 s to $0.26 \%$ in 2000 s, mainly due to a warm-dry climate trend in the eastern study region. 
5. A reduced positive relationship between precipitation and NDVI was observed in both the western and eastern regions over different time intervals; a change from a positive to negative relationship between temperature and NDVI was found in the eastern region, whereas the reverse trend occurred in the western region.

Future ecological restoration projects in this region should consider the climate trends and dynamic response of vegetation growth to climate observed in this study. This study will help the central government of China find integrated solutions for environmental recovery. Further studies are needed to investigate and understand the interactions between climate systems and vegetation variations by combining field experiments and process-based modeling in this region.

\section{Acknowledgements}

This work was financially supported by the National Natural Science Foundation of China (grant no.41301076), the National Basic Research Development Program of China (grant no. 2011CB952001 and 2012CB95570001) and the Training Foundation for Young Talents of Beijing, 2014 (grant no. 110632101).

\section{Author Contributions}

Bin He designed the study and wrote the main manuscript. Honglin Wang, Aifang Chen, and Qianfeng Wang processed and analyzed the data. All authors have reviewed the manuscript.

\section{Conflicts of Interest}

The authors declare no conflict of interest.

\section{References}

1. Cao, S. Why large-scale afforestation efforts in China have failed to solve the desertification problem. Environ. Sci. Technol. 2008, 42, 1826-1831.

2. Wu, Z.; Wu, J.; Liu, J.; He, B.; Lei, T.; Wang, Q. Increasing terrestrial vegetation activity of ecological restoration program in the Beijing-Tianjin sand source region of China. Ecol. Eng. 2013, 52, 37-50.

3. Liu, J.; Li, S.; Ouyang, Z.; Tam, C.; Chen, X. Ecological and socioeconomic effects of China's policies for ecosystem services. Proc. Natl. Acad. Sci. USA 2008, 105, 9477-9482.

4. Wang, Y.; Cao, S. Carbon sequestration may have negative impacts on ecosystem health. Environ. Sci. Technol. 2011, 45, 1759-1760.

5. Cao, S.; Sun, G.; Zhang, Z.; Chen, L.; Feng, Q.; Fu, B.; McNulty, S.; Shankman, D.; Tang, J.; Wang, Y. Greening China naturally. AMBIO 2011, 40, 828-831.

6. Qu, J.; Cao, S.; Li, G.; Niu, Q.; Feng, Q. Conservation of natural and cultural heritage in Dunhuang, China. Gondwana Res. 2014, 26, 1216-1221.

7. Piao, S.; Fang, J.; Liu, H.; Zhu, B. NDVI-indicated decline in desertification in China in the past two decades. Geophys. Res. Lett. 2005, 32, doi:10.1029/2004GL021764. 
8. Zhang, G.; Dong, J.; Xiao, X.; Hu, Z.; Sheldon, S. Effectiveness of ecological restoration projects in Horqin sandy land, China based on SPOT-VGT NDVI data. Ecol. Eng. 2012, 38, 20-29.

9. Cao, S.; Wang, G.; Chen, L. Questionable value of planting thirsty trees in dry regions. Nature 2010, $465,31$.

10. Wang, X.; Zhang, C.; Hasi, E.; Dong, Z. Has the three norths forest shelterbelt program solved the desertification and dust storm problems in arid and semiarid China? J. Arid Environ. 2010, 74, 13-22.

11. Zhu, L.; Zhu, X.; Yan, Q. Review on the shelter forest decline. Chin. J. Ecol. 2009, 28, 1684r1690.

12. Amri, R.; Zribi, M.; Lili-Chabaane, Z.; Duchemin, B.; Gruhier, C.; Chehbouni, A. Analysis of vegetation behavior in a North African semi-arid region, using spot-vegetation NDVI data. Remote Sens. 2011, 3, 2568-2590.

13. Wan, Z. NDVI anomaly patterns over Africa during the $1997 / 98$ ENSO warm event. Int. J. Remote Sens. 2001, 22, 1847-1859.

14. Menzel, A.; Sparks, T.H.; Estrella, N.; Koch, E.; Aasa, A.; Ahas, R.; ALM-KÜBLER, K.; Bissolli, P.; Braslavská, O.G.; Briede, A. European phenological response to climate change matches the warming pattern. Glob. Chang. Biol. 2006, 12, 1969-1976.

15. Asner, G.P.; Nepstad, D.; Cardinot, G.; Ray, D. Drought stress and carbon uptake in an Amazon forest measured with spaceborne imaging spectroscopy. Proc. Natl. Acad. Sci. USA 2004, 101, 6039-6044.

16. Ali, A.; de Bie, C.; Skidmore, A.K.; Scarrott, R.; Hamad, A.; Venus, V.; Lymberakis, P. Mapping land cover gradients through analysis of hyper-temporal NDVI imagery. Int. J. Appl. Earth Obs. Geoinf. 2013, 23, 301-312.

17. Fang, J.; Piao, S.; He, J.; Ma, W. Increasing terrestrial vegetation activity in China, 1982-1999. Sci. China Ser. C Life Sci. 2004, 47, 229-240.

18. Duan, H.; Yan, C.; Tsunekawa, A.; Song, X.; Li, S.; Xie, J. Assessing vegetation dynamics in the Three-North Shelter Forest Region of China using AVHRR NDVI data. Environ. Earth Sci. 2011, 64, 1011-1020.

19. Peng, S.; Chen, A.; Xu, L.; Cao, C.; Fang, J.; Myneni, R.B.; Pinzon, J.E.; Tucker, C.J.; Piao, S. Recent change of vegetation growth trend in China. Environ. Res. Lett. 2011, 6, 044027.

20. Chuai, X.; Huang, X.; Wang, W.; Bao, G. NDVI, temperature and precipitation changes and their relationships with different vegetation types during 1998-2007 in Inner Mongolia, China. Int. J. Climatol. 2013, 33, 1696-1706.

21. Guo, L.; Wu, S.; Zhao, D.; Yin, Y.; Leng, G.; Zhang, Q. NDVI-based vegetation change in Inner Mongolia from 1982 to 2006 and its relationship to climate at the biome scale. Adv. Meteorol. 2014, 2014, doi:10.1155/2014/692068.

22. Tucker, C.J.; Pinzon, J.E.; Brown, M.E.; Slayback, D.A.; Pak, E.W.; Mahoney, R.; Vermote, E.F.; El Saleous, N. An extended AVHRR 8-km NDVI dataset compatible with MODIS and SPOT vegetation NDVI data. Int. J. Remote Sens. 2005, 26, 4485-4498.

23. Jiang, N.; Zhu, W.; Zheng, Z.; Chen, G.; Fan, D. A comparative analysis between gimss NDVIg and NDVI3g for monitoring vegetation activity change in the Northern Hemisphere during 1982-2008. Remote Sens. 2013, 5, 4031-4044. 
24. Wang, J.; Dong, J.; Liu, J.; Huang, M.; Li, G.; Running, S.W.; Smith, W.K.; Harris, W.; Saigusa, N.; Kondo, H. Comparison of gross primary productivity derived from GIMMS NDVI3g, GIMMS, and MODIS in Southeast Asia. Remote Sens. 2014, 6, 2108-2133.

25. Miao, L.; Ye, P.; He, B.; Chen, L.; Cui, X. Future climate impact on the desertification in the dry land asia using AVHRR GIMMS NDVI3g data. Remote Sens. 2015, 7, 3863-3877.

26. Holben, B.N. Characteristics of maximum-value composite images from temporal AVHRR data. Int. J. Remote Sens. 1986, 7, 1417-1434.

27. Cressie, N. Statistics for Spatial Data; John Wiley \& Sons: Hoboken, NJ, USA, 1991.

28. Oliver, M.A.; Webster, R. Kriging: A method of interpolation for geographical information systems. Int. J. Geogr. Inf. Syst. 1990, 4, 313-332.

29. Hou, X. Vegetation atlas of China. Chinese Academy of Science, The Editorial Board of Vegetation Map of China; Scientific Press: Beijing, China, 2001.

30. Sen, P.K. Estimates of the regression coefficient based on kendall's tau. J. Am. Stat. Assoc. 1968, 63, 1379-1389.

31. Helsel, D.R.; Hirsch, R.M. Statistical Methods in Water Resources; Elsevier: Amsterdam, The Netherlands, 1992; Volume 49.

32. Kundzewicz, Z.W.; Robson, A.J. Change detection in hydrological records-A review of the methodology. Hydrol. Sci. J. 2004, 49, 7-19.

33. Krishnaswamy, J.; John, R.; Joseph, S. Consistent response of vegetation dynamics to recent climate change in tropical mountain regions. Glob. Chang. Biol. 2014, 20, 203-215.

34. Gocic, M.; Trajkovic, S. Analysis of changes in meteorological variables using Mann-Kendall and Sen's slope estimator statistical tests in Serbia. Glob. Planet. Chang. 2013, 100, 172-182.

35. Penman, H.L. Natural evaporation from open water, bare soil and grass. Proc. R. Soc. Lon. Ser. A. Math. Phys. Sci. 1948, 193, 120-145.

36. Meng, M.; Ni, J.; Zhang, Z. Aridity index and its applications in geo-ecological study. Acta Phytoecol. Sin. 2004, 28, 853-861.

37. Wu, S.; Yin, Y.; Zheng, D.; Yang, Q. Moisture conditions and climate trends in China during the period 1971-2000. Int. J. Climatol. 2006, 26, 193-206.

38. Shi, Y.; Shen, Y.; Kang, E.; Li, D.; Ding, Y.; Zhang, G.; Hu, R. Recent and future climate change in Northwest China. Clim. Chang. 2007, 80, 379-393.

39. Qian, W.; Lin, X. Regional trends in recent precipitation indices in China. Meteorol. Atmos. Phys. 2005, 90, 193-207.

40. Tabari, H.; Hosseinzadeh Talaee, P. Moisture index for Iran: Spatial and temporal analyses. Glob. Planet. Chang. 2013, 100, 11-19.

41. Piao, S.; Mohammat, A.; Fang, J.; Cai, Q.; Feng, J. NDVI-based increase in growth of temperate grasslands and its responses to climate changes in China. Glob. Environ. Chang. 2006, 16, 340-348.

42. Peng, S.; Piao, S.; Ciais, P.; Myneni, R.B.; Chen, A.; Chevallier, F.; Dolman, A.J.; Janssens, I.A.; Penuelas, J.; Zhang, G. Asymmetric effects of daytime and night-time warming on Northern Hemisphere vegetation. Nature 2013, 501, 88-92.

43. Nemani, R.R.; Keeling, C.D.; Hashimoto, H.; Jolly, W.M.; Piper, S.C.; Tucker, C.J.; Myneni, R.B.; Running, S.W. Climate-driven increases in global terrestrial net primary production from 1982 to 1999. Science 2003, 300, 1560-1563. 
44. Zhao, X.; Tan, K.; Zhao, S.; Fang, J. Changing climate affects vegetation growth in the arid region of the Northwestern China. J. Arid Environ. 2011, 75, 946-952.

45. Cao, S.; Chen, L.; Shankman, D.; Wang, C.; Wang, X.; Zhang, H. Excessive reliance on afforestation in China's arid and semi-arid regions: Lessons in ecological restoration. Earth Sci. Rev. 2011, 104, 240-245.

46. Wu, Y.; Zeng, Y.; Wu, B.; Li, X.; Wu, W. Retrieval and analysis of vegetation cover in the Three-North Regions of China based on MODIS data. Chin. J. Ecol. 2009, 28, 1712-1718.

47. Chen, T.; de Jeu, R.; Liu, Y.; van der Werf, G.; Dolman, A. Using satellite based soil moisture to quantify the water driven variability in NDVI: A case study over mainland Australia. Remote Sens. Environ. 2014, 140, 330-338.

48. Ibrahim, Y.Z.; Balzter, H.; Kaduk, J.; Tucker, C.J. Land degradation assessment using residual trend analysis of GIMMS NDVI3g, soil moisture and rainfall in Sub-Saharan west Africa from 1982 to 2012. Remote Sens. 2015, 7, 5471-5494.

49. Cao, S.; Ma, H.; Yuan, W.; Wang, X. Interaction of ecological and social factors affects vegetation recovery in China. Biol. Conserv. 2014, 180, 270-277.

50. Wang, Y.; Zhang, Q.; He, K.; Zhang, Q.; Chai, L. Sulfate-nitrate-ammonium aerosols over China: Response to 2000-2015 emission changes of sulfur dioxide, nitrogen oxides, and ammonia. Atmos. Chem. Phys. 2013, 13, 2635-2652.

51. Barriopedro, D.; Gouveia, C.M.; Trigo, R.M.; Wang, L. The 2009/10 drought in China: Possible causes and impacts on vegetation. J. Hydrometeorol. 2012, 13, 1251-1267.

52. Xu, X.; Piao, S.; Wang, X.; Chen, A.; Ciais, P.; Myneni, R.B. Spatio-temporal patterns of the area experiencing negative vegetation growth anomalies in China over the last three decades. Environ. Res. Lett. 2012, 7, 035701.

53. Ke, L.; Da-Bang, J.; Jian-Yong, M. Drought over China in the 21st century: Results of REGCM3. Atmos. Ocean. Sci. Lett. 2012, 5, 509-513.

54. Wang, L.; Chen, W. A CMIP5 multimodel projection of future temperature, precipitation, and climatological drought in China. Int. J. Climatol. 2014, 34, 2059-2078.

55. Peng, S.-S.; Piao, S.; Zeng, Z.; Ciais, P.; Zhou, L.; Li, L.Z.; Myneni, R.B.; Yin, Y.; Zeng, H. Afforestation in China cools local land surface temperature. Proc. Natl. Acad. Sci. USA 2014, 111, 2915-2919.

56. Govaerts, Y.; Lattanzio, A. Estimation of surface albedo increase during the eighties Sahel drought from Meteosat observations. Glob. Planet. Chang. 2008, 64, 139-145.

57. Hijmans, R.J.; Cameron, S.E.; Parra, J.L.; Jones, P.G.; Jarvis, A. Very high resolution interpolated climate surfaces for global land areas. Int. J. Climatol. 2005, 25, 1965-1978.

58. Wu, Z.; Dijkstra, P.; Koch, G.W.; Hungate, B.A. Biogeochemical and ecological feedbacks in grassland responses to warming. Nat. Clim. Chang. 2012, 2, 458-461.

(C) 2015 by the authors; licensee MDPI, Basel, Switzerland. This article is an open access article distributed under the terms and conditions of the Creative Commons Attribution license (http://creativecommons.org/licenses/by/4.0/). 